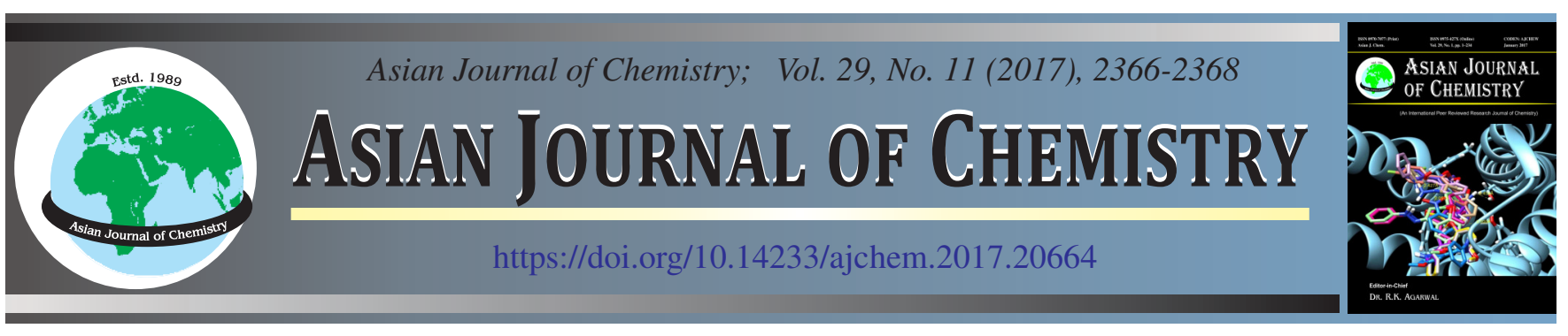

\title{
Characterization of Side Chain Liquid Crystal Polymers Type on Blending Polymer of Cholesteryl Acrylate with Methyl Phenyl Benzoyl Acrylate
}

\author{
AfrizaL $^{1, *}$, ErdaWATI $^{1}$, Asep Riswoko $^{2}$ and Siti Komariah ${ }^{1}$
}

${ }^{1}$ Department Chemistry, Faculty of Mathematics and Natural Science, University of State Jakarta, Jakarta, Indonesia

${ }^{2}$ Center for Material Technology, Agency for the Assessment and Application of Technology (BPPT), J1. MH.Thamrin 8 Jakarta, Indonesia

*Corresponding author: E-mail: afrizalkimia@gmail.com; afrizal@unj.ac.id

Received: 22 March 2017;

Accepted: 31 May 2017;

Published online: 29 September 2017;

AJC-18551

\begin{abstract}
Blending cholesteryl acrylate with methyl phenyl benzoyl acrylate was made by casting solution. Photopolymerization of blending product has been done by varying the UV radiation time were 60, 90, 120 and 150 min using UV curing technique. Curing process doing at temperature range of $55-60{ }^{\circ} \mathrm{C}$. Molecular weight $\left(\mathrm{M}_{\mathrm{w}}\right)$ of polymers was determined using gel permeation chromatography (GPC) showed the first peak at $\mathrm{M}_{\mathrm{w}} 2243$ and the second peak at $\mathrm{M}_{\mathrm{w}} 1160$ and the result of index polydisperity was 1.02-1.03. Polymer of liquid crystal acrylate from this study was characterisized by XRD, SEM-EDX and FTIR. The XRD pattern peaks appear at 60,90 and 120 min. SEM image shows the crosslink bonds are formed. EDX graph shows the polymer mixture containing carbon and oxygen. The FTIR spectrum raises wavenumber $1612.56 \mathrm{~cm}^{-1}$ indicates that the $\mathrm{C}=\mathrm{C}$ bonds contained in the polymer structure. Based on the result of characterization of polymer liquid crystal acrylate with XRD, SEM-EDX and FTIR shown that best product was from radiation time polymerization at $90 \mathrm{~min}$.
\end{abstract}

Keywords: Cholesteryl acrylate, Methyl phenyl benzoyl acrylate, Blending, Liquid crystal, UV curing.

\section{INTRODUCTION}

Cholesteryl acrylate and methyl phenyl benzoyl acrylate are group of liquid crystal monomer which had optical properties. Monomer cholesteryl acrylate is one of the cholesteric liquid crystalline polymers properties such as thermal stability and processability and these are potential candidates for optical equipment and methyl phenyl benzoyl acrylate is ferroelectric liquid crystal. Therefore, blends of two monomers cholesteryl acrylate and methyl phenyl benzoyl acrylate are great interest because of their combine optical properties [1]. In general process of blending between two materials with different physical properties be expected to produce a new material that may has many advantages [2].

Liquid crystal properties depend on temperature condition and phase of liquid crystal showed at certain range temperature. The product of blending monomer liquid crystal can only be used as UV-absorbing material to the application photosensor at room temperature [3]. Polymerization process of blending cholesteryl acrylate monomer liquid crystal with methyl phenyl benzoyl acrylate monomer liquid crystal can be fixation of structure liquid crystal for using at room temperature. That polymerization was called in situ polymerization using UV curing technique. Process in situ polymerization with UV radiation and the irradiated sample is heated at a certain temperature using initiator 2-hydroxy-2-methyl-1-phenylpropane. Several factors influence of polymerization process are: type initiator, initiator amount, duration of radiation and temperature during radiation $[4,5]$.

This research reports the effect of radiation time on polymer producted. Characterization of polymer liquid crystal performed by characterization of functional groups that explain how the alkene group in the acrylic polymerization was reduced. Characterization of the surface, cross section of the polymers and crystallinities determining the molecular weight of the resulting polymer. The results be expected to be a references for applied technologies further to the results of the resulting polymer product as UV absorber.

\section{EXPERIMENTAL}

Synthesis of monomer cholesteryl acrylate and methyl phenyl benzoyl acrylate used reported by Hikam et al. [6] has been modified. Materials for synthesis: cholesterol, $(S)-(+)-$ 2-methyl-butanoic, hydroquinone, N,N'-dicyclohexylcarbodiimidy (DCC), N,N-dimethylpiridine-4-amine (DMAP), dichloromethane, PTSA ( $p$-toluene-sulfonate), $\mathrm{KOH}$, concentrated $\mathrm{HCl}$, ethanol, methanol, benzene, $\mathrm{KI}, \mathrm{K}_{2} \mathrm{CO}_{3}$, acrylic acid and petroleum ether was obtained from Merck. Chloro- 
butyl acetate and ethyl $p$-hydroxy benzoate was obtained from Aldrich. Analysis of thin-layer chromatography (TLC) using a $0.2 \mathrm{~mm}$ aluminum plate with silica gel $60 \mathrm{~F}-254$ obtained from Merck. Column chromatography using silica gel 60 with 70-230 mesh obtained from Merck.

Process blending of monomer cholesteryl acrylate with methyl phenyl benzoyl acrylate by mixing two monomers in 1:1 ratio, respectively until homogeneous. After that added darocore 1173 as an initiator. The process of blending process using casting solution technique [7]. Both monomers are dissolved using dichloromethane solvent. Homogeneous solution was printed on the surface of the glass that has been coated with polyimide. Blends of cholesteryl acrylate with methyl phenyl benzoyl acrylate was heated at $55^{\circ} \mathrm{C}$ for $30 \mathrm{~min}$ to remove the solvent and stored for $24 \mathrm{~h}$ in a desiccator to maximize that the film does not contain solvent blending.

Instrument for characterization of group function of polymer acrylate was Fourier transformed infrared (FTIR) spectrometer by Perkin Elmer. For surface characterization of polymer using scanning electron microscopy (SEM). The molecular weight of polymer were determined by gel permeation chromatography (GPC).

\section{RESULTS AND DISCUSSION}

Polymerization of blending product from cholesteryl acrylate with methyl phenyl benzoyl acrylate by solution casting method is printed at transparent glass plate that has been coated by the polyimide. This polymerization technique is referred to as UV curing technique aimed at fixing the structure of the polymer. The process of polymerization using initiator 2-hydroxy-2-methyl-1-phenyl-propane or commonly known photoinitiator darocure 1173. The fixation for oriented of liquid crystal molecules acrylate polymers using glass substrate surfaces that had been coated type of substance that fixing the main chain (alignment material) [8]. Illustration of photopolymerization process using UV curing technique can be seen in Fig. 1.

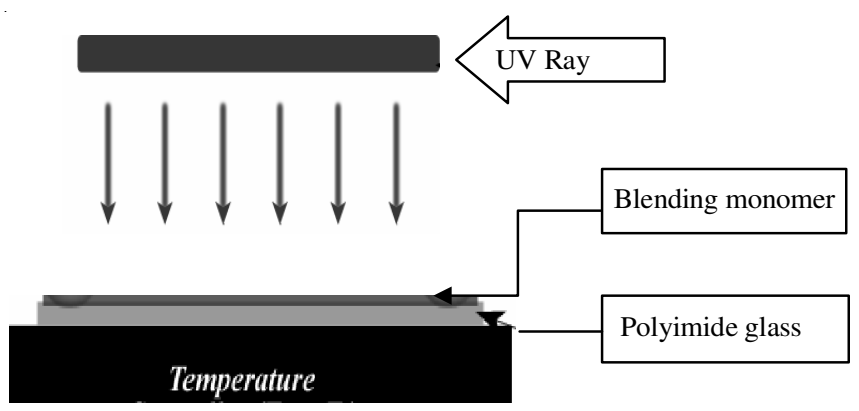

Fig. 1. Photopolymerization process of blending liquid crystal

Polymer liquid crystal acrylate from this research is in situ polymerization which polymerization process as bulk polymer by the fixation conditions of the molecular structure. Study liquid crystalline polymer by Kato et al. [9] explained type liquid crystal polymer are main chain liquid polymer (MCLCPs) and side chain liquid crystal polymers (SCLCPs). Type SCLCPs generally formed from addition polymerization mesogen liquid crystal as a side chain. This work involved the polymer liquid crystal acrylate as addition plymerization, therefore liquid crystal polymer blending monomer cholesteryl acrylate with methyl phenyl benzoyl acrylate is SCLCPs type polymer.

Molecular weight of polymer liquid crystals acrylate was determined by gel permeation chromatography (GPC). The molecular weight of the polymer can be interpreted in expression of molecular weight average number $\left(\mathrm{M}_{\mathrm{n}}\right)$ and weight average molecular weight $\left(\mathrm{M}_{\mathrm{w}}\right)$. GPC measurement results can also tell polydispersity index (PI) value of the ratio $M_{w} / M_{n}$. Polydispersity index (PI) can be used as an indication of width of the area within a molecular weight of the polymer sample and also based on the literature value of PI can determine the type of polymerization occurs [10].

Type of polymer chain of side chain liquid crystal polymers (SCLCPs) can be confirmed through the analysis of crosssectional surface texture of polymers [11]. Surface characterization was performed by scanning electron microscopy (SEM). SEM images (Fig. 2) of surface of polymers not different, polymer lamella from three polymers clear seen. Polymer was resulted at radiation time $60 \mathrm{~min}$ and $90 \mathrm{~min}$ showed chain polymer making cross linking. Polymer liquid crystals were made at radiation time at 120 and $150 \mathrm{~min}$. It seems polymerization process has exceeded the optimum time, because surface of polymer looks thick and dense. Surface images of polymer seems to accumulate or damaged because of the possibility of breaking up some of the polymer chains.
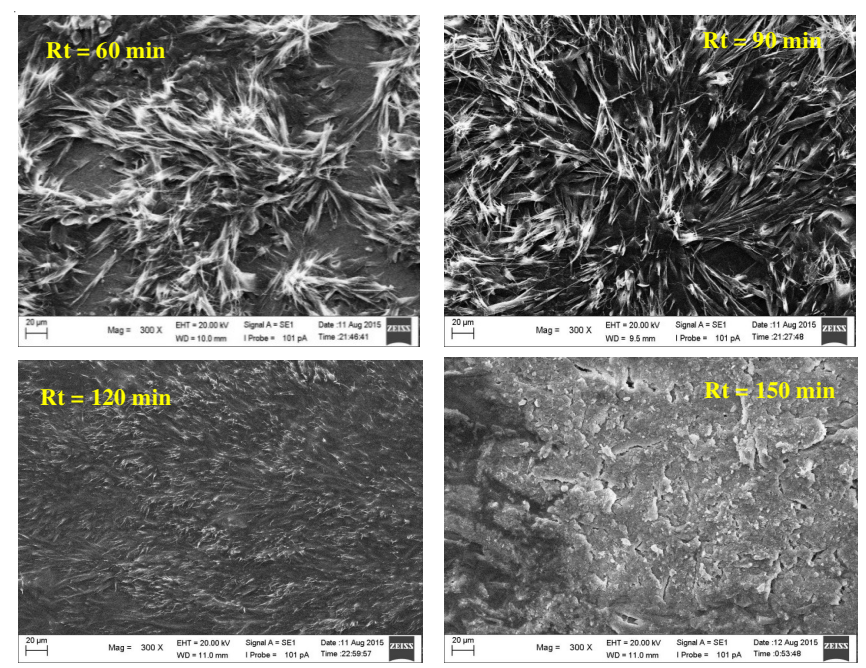

Fig. 2. SEM images of polymer at radiation time (Rt) 60, 90, 120 and 150 $\min$

For the complete analysis surface of polymer liquid crystal acrylate, that compare with the characterization of polymer by X-ray diffraction (XRD). In general, polymers has amorphous and crystalline region [12]. The result of characterization of polymer by XRD showed that polymer from radiation time at 60,90 and 120 min appear a little sharp peak at $2 \theta>30$ and polymer from radiation time at $150 \mathrm{~min}$ appear not peak in XRD patterns generated in Fig. 3 .

The XRD patterns can be seen that peaks of polymer with the irradiation time for $60,90,120$ and 150 min showed the peaks for polymer are not different. XRD peaks of the product polymer with Rt 60 min showed peak spacing values d $(\AA)$ in shrap peak at 2, 2.02, 4.24 and 31.7; there are 4 peaks. But in 


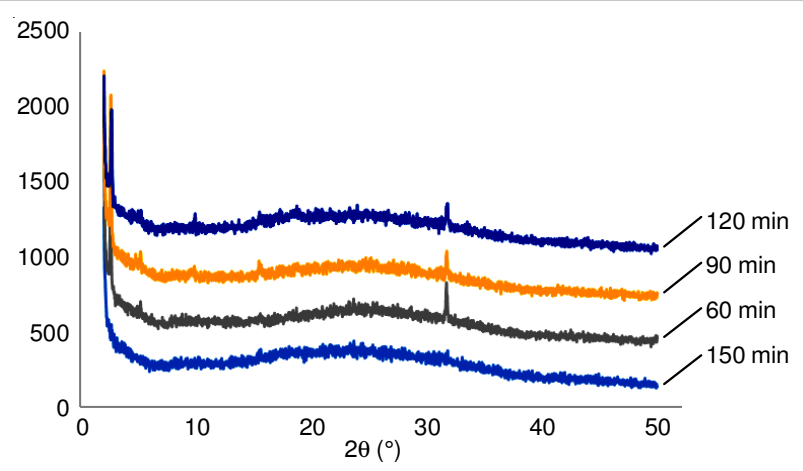

Fig. 3. XRD patterns polymer liquid crystals of blending cholesteryl acrylate/methyl phenyl benzoyl acrylate $(\mathrm{ChA} / \mathrm{MFA})\left(\mathrm{R}_{\mathrm{t}}=150 \mathrm{~min}\right)$

XRD pattern of the product polymer with Rt 90 min showed peak spacing values $d(\AA)$ in shrap peak at 2, 2.58, 4.32, 9.34, 15.44 and 31.681 there are 6 peaks. XRD pattern of the product polymer with $R_{t} 120$ min showed peak spacing values $d(\AA)$ in shrap peak at 2, 2.02, 9.84, 15.44, 16.92, 18.62, 23.3 and 31.72. However XRD pattern of the product polymer with Rt 150 min showed only one sharp peak with spacing values d ( $\mathrm{A})$ at 2.00.

The phenomenon interested from XRD pattern, which polymer result in this research crosslinking of polymer can be changed because radiation time in respectively polymer. Almost all polymers is semi-crystalline morphology, which any crystallion region and amorphous region. According to Rivnay et al. [13] semi-crystalline polymers exhibit disordered amorphous regions coexisting with crystalline regions. UV ray can effect on morphology liquid crystalline polymer were network formed and presence of straight-chain polymer of regular and amorphous phase in the polymer seen a chain or a irregular shape of the polymer fibers.

The goal of polymerization of blending liquid crystal acrylate in this work is the structure fixation nematic cholesteryl acrylate and smectic methyl phenyl benzoyl acrylate. Process of UV curing at $60 \mathrm{~min}$ radiation time not yet optimal to fixation that structure. The reason only 4 sharp peaks in XRD pattern. Therefore UV curing at $90 \mathrm{~min}$ radiation time has optimal to fixation that structure. Comparison with UV curing at 120 min the fixation has broken because crystallized region disappeared. Product polymer at radiation time at $150 \mathrm{~min}$ appeared fixation structure all broken and that phenomenon we can see from XRD pattern there are no sharp peak.

Gel permeable chromatography showed the first peak at molecular weight $\left(\mathrm{M}_{\mathrm{w}}\right) 2243$ and the second peak at $\mathrm{M}_{\mathrm{w}} 1160$. Polydispersity index (PDI) for the first peak is 1,029431,03691 and for the second peak is 1,02099-1,02514. Based on PDI information, it is concluded that polymerization process is the addition polymerization. Characterization with Fourier transformed infrared showed weak peak at wave number $1612.56 \mathrm{~cm}^{-1}$ that interpreted lessening double bonding in $\mathrm{C}=\mathrm{C}$. Based on result of GPC, SEM, XRD and FTIR this research for curing process at 90 min give the good performance.

\section{Conclusion}

Polymerization process using initiator darocure 1173 with UV curing technique. Polymer was resulted at radiation time
60 and 90 min showed chain polymer making cross linking. Polymer liquid crystals were made at radiation time at 120 and $150 \mathrm{~min}$ and it seems that the polymerization process has exceeded the optimum time, because surface of polymer looks thick and dense. The XRD patterns can be seen that peaks of polymer with the irradiation time for $60 \mathrm{~min}, 90 \mathrm{~min}, 120 \mathrm{~min}$ and $150 \mathrm{~min}$ showed the peaks for polymer are not different. XRD peaks of the product polymer with Rt 60 min showed peak spacing values $d(\AA)$ in shrap peak at 2, 2.02, 4,24 and 31.7; there are 4 peaks. But in XRD pattern of the product polymer with Rt 90 min showed peak spacing values $d(\AA)$ in shrap peak at 2, 2.58, 4.32, 9.34, 15.44 and 31.68; there are 6 peaks. XRD pattern of the product polymer with Rt $120 \mathrm{~min}$ showed peak spacing values $d(\AA)$ in shrap peak at 2, 2.02, 9.84, 15.44, 16.92, 18.62, 23.3 and 31.72. GPC Result showed the first peak at molecular weight $\left(\mathrm{M}_{\mathrm{w}}\right) 2243$ and the second peak at $\mathrm{M}_{\mathrm{w}}$ 1160. Polydispersity index (PDI) for the first peak is 1,02943-1,03691 and for the second peak is 1,02099-1,02514. Characterization with Fourier transformed infrared showed weak peak at wave number $1612.56 \mathrm{~cm}^{-1}$ that interpreted lessening double bonding in $\mathrm{C}=\mathrm{C}$.

\section{ACKNOWLEDGEMENTS}

This research was supported by SKIM Fundamental Funding from Kementerian Riset Teknologi Dan Pendidikan Tinggi Republik Indonesai Number : 08/SP2H/DRPM/LP-UNJ/PF/ III/2016 Tanggal 22 Maret 2016.

\section{REFERENCES}

1. Afrizal, M. Hikam, B. Soegiyono and A. Riswoko, Procedia Chem., 16, 525 (2015);

https://doi.org/10.14233/ajchem.2016.19326.

2. C. Lee and K. Song, Asian J. Chem., 26, 8057 (2014); https://doi.org/10.14233/ajchem.2014.17098.

3. J.P. Lagerwall and F. Giesselmann, ChemPhysChem, 7, 20 (2006); https://doi.org/10.1002/cphc.200500472.

4. S. Lépinay, K. Kham, M.-C. Millot and B. Carbonnier, Chem. Pap., 66, 340 (2012);

https://doi.org/10.2478/s11696-012-0134-6.

5. M. Hagar, S.M. Soliman, R.A. Massoud and M.M. Zaid, Asian J. Chem., 28, 351 (2016);

https://doi.org/10.14233/ajchem.2016.19326.

6. Afrizal, M. Hikam, B. Soegiyono and A. Riswoko, J. Chem. Chem. Eng., 6, 1051 (2012); https://doi.org/10.17265/1934-7375/2012.12.001.

7. H.P. Zhang, P. Zhang, M. Sun, H.Q. Wu, Y.P. Wu and R. Holze, Z. Phys. Chem., 221, 1039 (2007);

https://doi.org/10.1524/zpch.2007.221.8.1039.

8. K. Kishikawa, A. Hirai and S. Kohmoto, Chem. Mater., 20, 1931 (2008); https://doi.org/10.1021/cm702998y.

9. T. Kato, N. Mizoshita and K. Kishimoto, Angew. Chem. Int. Ed., 45, 38 (2006); https://doi.org/10.1002/anie.200501384

10. A. Zen, M. Saphiannikova, D. Neher, J. Grenzer, S. Grigorian, U. Pietsch, U. Asawapirom, S. Janietz, U. Scherf, I. Lieberwirth and G. Wegner, Macromolecules, 39, 2162 (2006); https://doi.org/10.1021/ma0521349.

11. L. Sabbatini, E. Bittrich, S. Cometa, E. De Giglio and R. Di Mundo, Polymer Surface Characterization, Walter de Gruyter GmbH \& Co KG, (2014).

12. M. Rheinstädter, L. Toppozini and H. Dies, Z. Phys. Chem., 228, 1105 (2014); https://doi.org/10.1515/zpch-2014-0541.

13. J. Rivnay, R. Noriega, J.E. Northrup, R.J. Kline, M.F. Toney and A. Salleo, Phys. Rev. B, 83, 121306 (2011); https://doi.org/10.1103/PhysRevB.83.121306 